УДК 796.0

\title{
ДВИГАТЕЛЬНАЯ АКТИВНОСТЬ ДОШКОЛЬНИКА В УСЛОВИЯХ СЕМЕЙНОГО ВОСПИТАНИЯ
}

\section{Арутюнян Т.Г.}

Сибирский государственный аэрокосмический университет имени академика М.Ф. Решетнева, Сибирский федеральный университет, Главное управление образования администрации, Красноярский информационно-методический иентр, Красноярск, e-mail: nayka.07@mail.ru

Цель исследования - применить мониторинг как средство совершенствования физического здоровья и физической подготовленности в условиях семейного воспитания. Гипотеза исследования. Система формирования активного двигательного режима ребенка в семье от 0 до 6 лет будет целесообразной и эффективной, если: подтвердить научное положение Л.К. Сидорова в части выявления путей формирования и реализации двигательной потребности индивида; подтвердить научное положение Г.Н. Голубевой в части, предусматривающей непосредственное участие родителей детей в формировании активного двигательного режима. В результате исследования подтверждено научное положение Г.Н. Голубевой. Апробирована четвертая организационная система физкультурного образования детей дошкольного возраста в семье, где ребенок посещает дошкольное учреждение, детский сад и специализированную спортивную школу. Результаты физкультурного образования ребенка дошкольного возраста в семье выше результатов тестирования контрольных и экспериментальных групп современных исследователей. На основании разработок Л.К. Сидорова сформирована потребность в движениях в условиях семейного воспитания у ребенка от 0 до 6 лет при помощи среды, которая его окружает повседневно на уровне подсознания - в бессознательном поле.

Ключевые слова: дошкольник, физкультура, семья, движение, образование, потребность

\section{MOTOR ACTIVITY PRESCHOOLER IN TERMS OF FAMILY EDUCATION}

\section{Arutyunyan T.G.}

Siberian State Aerospace University named after academician M.F. Reshetnev, Siberian Federal University", Department of Education of the city administration of Krasnoyarsk, Krasnoyarsk information-methodical center, Krasnoyarsk, e-mail:nayka.07@mail.ru

The purpose of the study apply as a tool to improve the monitoring of physical health and physical fitness in terms of family upbringing. Hypothesis of the study. System of formation of the active motor mode -child from 0 to 6 years old will be effective and efficient if: confirm the scientific position LK Sidorova in identifying ways of developing and implementing the motor needs of the individual; confirm the scientific position GN Golubeva part in providing direct participation of parents of children in the formation of the active motor mode. The study confirmed scientific position GN Golubeva. Tested fourth organizational system of physical education of preschool children in a family where the child attends preschool, kindergarten and specialized sports school. Results of physical education preschool child - a family of test results above the control and experimental groups of modern researchers. Based LK Sidorova formed the need for movements in terms of family upbringing of the child from 0 to 6 years using the environment that surrounds him every day at the subconscious level - in the field unconscious.

Keywords: preschool, physical education, family, exercise, education, need

На протяжении всей истории человечества существует стремление к укреплению здоровья будущего поколения. В современном обществе существует проблема ухудшения состояния здоровья детей дошкольного возраста и снижающийся уровень их физических кондиций.

О.В. Казак (теперь О.В. Дмух) выявила три организационные системы физкультурного образования детей дошкольного возраста, а именно: в детских садах, в специализированных клубах и школах и в семьях, где дети не посещают дошкольные учреждения [2].

Г.Н. Голубева определяет приоритетным формирование потребности в движениях, которое на основании ее исследований наиболее эффективно в антенатальный период. Считает, что эффективность снижается при переходе от одного периода адаптации к другому по мере роста ребенка. И установила возрастающую роль физкультурно-оздоровительных технологий, к которым относятся:

- физкультурно-оздоровительные методики;

- развивающая обстановка;

- стимулирование двигательной активности;

- параметры организованной двигательной активности;

- параметры самостоятельной двигательной активности [1].

Л.К. Сидоров считает, что сформированность потребности в движении не нуждается в столь серьезном материально-финансовом обеспечении, для человека достаточно будет той среды, которая его окружает повседневно (квартирные условия, скверы, парки, тропинки, вспомогательные средства). В методологии построения системы физического воспита- 
ния первоосновой будет сформированность такого состояния двигательной потребности, при котором необходимость в занятиях физической культурой будет оцениваться не на уровне сознания, а на уровне подсознания - в бессознательном поле (он чувствует, что иначе нельзя). Только такой уровень сформированности двигательной потребности, по мнению Л.К. Сидорова, позволит успешно решить все стоящие перед физическим воспитанием задачи [7].

Кроме этого, необходимо опираться при формировании социальной потребности в двигательной активности на важное научное положение высокой восприимчивости детским организмом воздействий внешней социальной среды [3].

Объект исследования. Двигательный режим ребенка от 0 до 6 лет в условиях семейного воспитания.

Предмет исследования. Средства, методы, формы и факторы формирования активного двигательного режима и двигательной потребности ребенка от 0 до 6 лет в условиях семейного воспитания.

На основании вышеизложенного определена цель: применить мониторинг как средство совершенствования физического здоровья и физической подготовленности в условиях семейного воспитания.

Гипотеза исследования. Система формирования активного двигательного режима ребенка в семье от 0 до 6 лет будет целесообразной и эффективной, если:

- подтвердить научное положение Л.К. Сидорова в части выявления путей формирования и реализации двигательной потребности индивида и внесения коррективы в структуру, содержание, методическое и организационное обеспечение образовательного процесса по физическому воспитанию детей от 0 до 6 лет;

- подтвердить научное положение Г.Н. Голубевой в части, предусматривающей непосредственное участие родителей детей в формировании активного двигательного режима в периоды: антенатальный и до начала посещения дошкольного образовательного учреждения. Учитывая при этом параметры двигательной активности (уровень: высокий, средний, низкий; тип подвижности: взрывной, силовой, циклический, пластический), особенности развивающей среды, а главной целью педагогических мероприятий станет формирование у ребенка внутренней потребности в двигательной активности, способствующей успешной адаптации к условиям внешней среды.

Определены задачи:

- на основании разработок О.В. Казак (теперь О.В. Дмух) апробировать четвертую организационную систему физкультурного образования детей дошкольного возраста в семье, где ребенок посещает дошкольное учреждение, детский сад и специализированную спортивную школу;

- на основании разработок Л.К. Сидорова сформировать потребность в движениях в условиях семейного воспитания у ребенка от 0 до 6 лет при помощи среды, которая его окружает повседневно на уровне подсознания - в бессознательном поле;

- сравнить результаты тестирования контрольных и экспериментальных групп с результатом физкультурного образования ребенка дошкольного возраста - в семье.

Методы исследования. Имеют под собой теоретическую основу положений Л.П. Матвеева, В.И. Ляха, Д.Г. Миндиашвили, Ю.И. Евсеева, А.М. Максименко, В.Ф. Прядченко, Я.К. Коблева, С.А. Хазовой, А.И. Завьялова, К.К. Маркова, Л.К. Сидорова, В.А. Адольфа, Г.Я. Галимова, А.В. Гаськова, В.А. Стрельникова, В.Г. Шилько, О.И. Загревского, Л.В. Капилевича, Б.Х. Ланды, Х.-Д.Н. Ооржака, М.Д. Кудрявцева, А.Н. Савчука, К.С. Лавриченко, О.В. Волковой, В.А. Кузьмина, И.А. Медведева, М.И. Шиловой, О.Н. Московченко, А.Р. Шакирова, М.И. Бордукова, Г.С. Саволайнен, Е.В. Панова, О.В. Казак, В.В. Денискина, О.М. Леонтьевой, С.Б. Элипханова, Д.А. Коряковской, В.Ю. Зиамбетова, С.Г Александрова, В.И. Усакова и других.

Методология теоретических положений исследования охарактеризована тесным соединением философских, общенаучных, отраслевых и конкретно-исследовательских принципов, подходов и методов.

В процессе исследования будут использованы: системный подход, структурнофункциональный подход, моделирование, классификационный подход, библиографический поиск, сбор и систематизация документальной информации, опросные методы, эксперимент педагогического характера, методы наблюдения и регистрации фактов, статистические методы обработки данных и другие методы.

Научная новизна результатов исследования заключается в постановке и решении проблемы качественной физической подготовки. В центре ставится выполнение физического упражнения в условиях семьи. В разработке четвертой организационной системы физкультурного образования детей дошкольного возраста в семье, где ребенок посещает дошкольное учреждение, детский сад и специализированную спортивную школу, ее теоретическом обосновании и экспериментальной апробации, ставшей предметом комплексного научного исследования. 


\section{Материалы и методы исследования}

До 3 лет в раннем возрасте ребенок растет и развивается очень быстро, но сопротивляемость неблагоприятным влияниям среды невысока. Возникает опасность заболеваний, и забота о здоровье выходит на первый план. Усредненные двигательные возможности по определению А.М. Максименко выглядят примерно так. Первые три месяца жизни движения ребенка беспорядочны и неосознанны. На шестом попытки переворачиваться, ползать, вставать, сидеть. К концу года или раньше начинает ходить. Развитие движений происходит в основном за счет подражания действиям окружающих. В третий и четвертый годы жизни осознанно выполняются прыжки на двух и одной ноге, бег, лазание по гимнастической стенке, ловля мяча и т.д. На пятом году появляется способность овладевать целостными и аналитическими движениями. Шестой и седьмой годы отмечаются замедлением темпов роста силовых возможностей, но выносливость и координационные способности продолжают возрастать [4].

Д.Г. Миндиашвили и А.И. Завьялов определяют важное направление в физическом воспитании дошкольников, заключающееся в использовании мяча Ребенок сам выбирает мяч как средство своего развития. Манипуляции с мячом укрепляют пальцы и кисти рук. Также метание оказывает положительное физиологическое воздействие на организм ребенка развитие мозга, глазомера, равновесия [5].

Значимый внешний фактор, определяющий развитие ребенка - это семейное воспитание. Ответственность за физическое, нравственное, умственное, социальное воспитание и развитие несут родители [1].

Опираясь на вышеназванные положения - формируем четвертую организационную систему физкультурного образования детей дошкольного возраста - в семье, где ребенок посещает дошкольное учреждение, детский сад и специализированную спортивную школу.

Задача родителей правильно распределить время для развития ребенка по каждой неделе и на каждый день. Предлагаем вниманию недельный режим Максима Тиграновича Арутюняна 2008 года рождения. Следует отметить, что активность Максима является повышенной. От 0 до 1 года прогулки в коляске около 8 часов ежедневно. В 11 месяцев был сделан первый шаг, а в 1 год в домашних условиях был совершен первый удар ногой по мячу. До 3,5 лет ежедневные прогулки от 3 до 8 часов. Во время прогулок в летний период игра в футбол, лазания в детском городке, 2,5 часовые пешие прогулки по острову Отдыха (Красноярск), езда на трехколесном велосипеде, висы, ходьба с удержанием равновесия, катание на роликовых коньках и другое. Кроме этого выезды за город в сельскую местность и ежедневные купания в надувном бассейне. В зимний период катание на лыжах, санках, санках-ледянках, пешие прогулки, игры в детском городке, игра в хоккей и другое.

Режим дня после 3,5 лет. Посещение детского сада с понедельника по пятницу. Секция по плаванию понедельник и четверг, среда и суббота подготовительная школа. В выходные дни активный отдых в зависимости от времени года с использованием средств физического воспитания, обозначенных выше.

Соглашаясь с научным положением о высокой роли родителей, не можем исключить роль дедушки в данном конкретном случае. У Максима наблюдается устойчивый интерес и потребность к игре в футбол (ри- сунок), который ему привил дедушка Гарри Грантович Арутюнян в свое время игравший в команде «Спартак» Орджоникидзе (теперь Владикавказ - Алания).

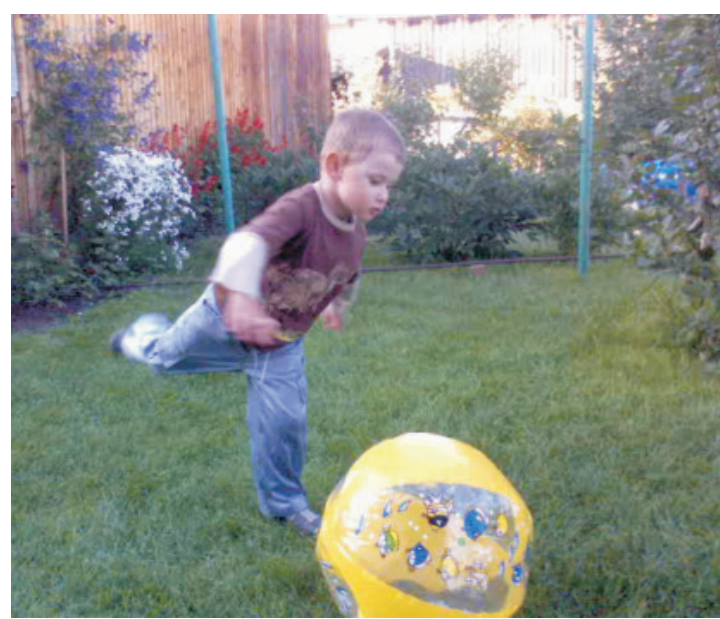

\section{Результаты исследования и их обсуждение}

Изучив современные результаты исследования В.М. Кравченко, в экспериментальных группах отмечен наиболее высокий результат в прыжках с места детей 6 лет 130 сантиметров [3]. По данным Л.И. Пензулаевой - 86,3-108,7 сантиметров, по данным Е.Н. Вавиловой - 93, $\pm 14,9$ сантиметров, по данным А.Б. Лагутина плохо - 109 сантиметров и меньше, удовлетворительно 110-124 сантиметров, хорошо 125-138 сантиметров, отлично 139 и больше сантиметров [6]. Лучший результат в МБДОУ № 103, участвовавшему в Красноярской городской программе «Мониторинг физического здоровья и физической подготовленности школьников» 2012-2013 учебном году [8] - это 112 сантиметров, повторное тестирование мальчиков подготовительной к школе группе. Максим Арутюнян показал результат выше экспериментальных данных В.М. Кравченко, Л.И. Пензулаевой, Е.Н. Вавиловой, Красноярской городской программы, но подходит под показания А.Б. Лагутина. Его прыжок с места 132 сантиметра по данным А.Б. Лагутина - хороший результат. Работа А.Б. Лагутина «Двигательные задания и упражнения для физического развития детей 4-6 лет» выпущена в 1996 г., предположительно, что исследования проводились ранее в условиях стабильной политической и экономической обстановки в стране, с хорошо функционирующей системой физического воспитания [6]. Возможно, в современных условиях данный результат можно назвать отличным.

Средние показатели метания теннисного мяча вдаль по данным Л.И. Пензулаевой с пределами колебаний мальчики 
6 лет - 9,32 $\pm 2,1$ м, то есть максимальная дальность 11,33 м. По информации сайта Rackets.ru средний вес мяча для большого тенниса, составляет 56-59 грамм. М.Т. Арутюнян бросил на дальность мяч для игры в «Русский хоккей» на 12,85 м, вес которого составляет 60-65 грамм по данным онлайнэнциклопедии (http://encyclopaedia.biga.ru/ enc/sport/HOKKE_S_MYACHOM.html). Peзультат выше при большем весе мяча.

И еще один вид тестирования бег $10 \mathrm{M}$. со старта. Средние показатели Е.Н. Вавиловой [6] для мальчиков 6 лет составляют $2,6 \pm 0,02$ с, в то время как М.Т. Арутюнян показал результат 2,5 секунды.

Тестирования в условиях семьи были проведены впервые, поэтому нет возможности в настоящий момент определить темпы прироста физических качеств. Данное исследование будет продолжено с учетом данного недостатка.

\section{Выводы}

1) подтверждено научное положение Л.К. Сидорова в части выявления путей формирования и реализации двигательной потребности индивида. В структуру содержания, методического и организационного обеспечения образовательного процесса по физическому воспитанию детей от 0 до 6 лет в семье внесены коррективы;

2) подтверждено научное положение Г.Н. Голубевой в части, предусматривающей непосредственное участие родителей детей в формировании активного двигательного режима в период до начала посещения дошкольного образовательного учреждения. Учитывались при этом параметры двигательной активности (уровень: высокий, тип подвижности: взрывной), особенности развивающей среды. Главной целью педагогических мероприятий стало формирование у ребенка внутренней потребности в двигательной активности, способствующей успешной адаптации к условиям внешней среды;

3) апробирована четвертая организационная система физкультурного образования детей дошкольного возраста в семье, где ребенок посещает дошкольное учреждение, детский сад и специализированную спортивную школу. Результаты физкультурного образования ребенка дошкольного возраста - в семье выше результатов тестирования контрольных и экспериментальных групп современных исследователей;

4) на основании разработок Л.К. Сидорова сформирована потребность в движениях в условиях семейного воспитания У ребенка от 0 до 6 лет при помощи среды, которая его окружает повседневно на уровне подсознания - в бессознательном поле.

\section{Список литературы}

1. Голубева Г.Н. Формирование активного двигательного режима ребенка (до 6-ти лет) средствами физического воспитания в основные периоды адаптации к условиям среды: автореф. дис. ... д-ра пед. наук. - Малаховка: МГАФК, 2008. - 50 с.

2. Казак О.В. Оптимизация двигательной активности дошкольников в условиях семейного воспитания: дис. ... канд. пед. наук. - Красноярск: КГПУ им. В.П. Астафьева, 2005. - 207 с.

3. Кравченко В.М. Формирование здоровья и физической культуры дошкольников: учебно-методическое пособие. - Красноярск: КГПУ им. В.П. Астафьева, 2011. - 110 с.

4. Максименко А.М. Теория и методика физической культуры: учебник. - М.: Физическая культура, 2005. - 533 с.

5. Миндиашвили Д.Г. Завьялов, А.И. Формирование спортивно-образовательного пространства в условиях модернизации Российского общества (на примере подрастающего поколения Сибирского региона): монография. - Красноярск: КГПУ им. В.П. Астафьева, 2011. - 415 с.

6. Полтавцева Н.В., Гордова Н.А. Физическая культура в дошкольном детстве: пособие для инструкторов физкультуры и воспитателей, работающих с детьми 4-5 лет. - М.: Просвещение, 2004. - 272 с.

7. Сидоров Л.К. Формирование и реализация двигательной потребности в системе непрерывного физкультурного образования: дис. ... д-ра пед. наук. - Улан-Удэ: БГУ, 2002. - $320 \mathrm{c}$

8. Программа «Мониторинг физического здоровья и физической подготовленности школьников»/Главное управление образования администрации города Красноярска. URL: http://krasobr.admkrsk.ru/doc.asp?id = 3598 (дата обращения: 11.03.2014).

\section{References}

1. Golubeva G.N. Formirovanie aktivnogo dvigatelnogo rezhima rebenka (do 6-ti let) sredstvami fizicheskogo vospitaniya $\mathrm{v}$ osnovnyie periodyi adaptatsii $\mathrm{k}$ usloviyam sredyi: avtoreferat dissertatsii na soiskanie uchenoy stepeni doktora pedagogicheskih nauk. Malahovka: MGAFK, 2008. 50 p.

2. Kazak O.V. Optimizatsiya dvigatelnoy aktivnosti doshkolnikov v usloviyah semeynogo vospitaniya: dissertatsiya na soiskanie uchenoy stepeni kandidata pedagogicheskih nauk/ O.V. Kazak. Krasnoyarsk: KGPU im. V.P. Astafeva, 2005. 207 p.

3. Kravchenko, V.M. Formirovanie zdorovya i fizicheskoy kulturyi doshkolnikov: uchebno-metodicheskoe posobie / V.M. Kravchenko. Krasnoyarsk: KGPU im. V.P. Astafeva, 2011. 110 p.

4. Maksimenko, A.M. Teoriya i metodika fizicheskoy kulturyi: uchebnik/ A.M. Maksimenko. Moskva: Fizicheskaya kultura, 2005. 533 p.

5. Mindiashvili, D.G. Zavyalov, A.I. Formirovanie sportivno-obrazovatelnogo prostranstva $\mathrm{v}$ usloviyah modernizatsii Rossiyskogo obschestva (na primere podrastayuschego pokoleniya Sibirskogo regiona): monografiya/D.G. Mindiashvili, A.I. Zavyalov. Krasnoyarsk: KGPU im. V.P. Astafeva, 2011. 415 p.

6. Poltavtseva, N.V. Gordova, N.A. Fizicheskaya kultura $\mathrm{v}$ doshkolnom detstve: posobie dlya instruktorov fizkulturyi i vospitateley, rabotayuschih s detmi 4-5 let / N.V. Poltavtseva, N.A. Gordova. Moskva: Prosveschenie, 2004. 272 p.

7. Sidorov, L.K. Formirovanie i realizatsiya dvigatelnoy potrebnosti $\mathrm{v}$ sisteme nepreryivnogo fizkulturnogo obrazovaniya: dissertatsiya na soiskanie uchenoy stepeni doktora pedagogicheskih nauk/ L.K. Sidorov. Ulan-Ude: BGU, 2002. 320 p.

8. Programma «Monitoring fizicheskogo zdorovya i fizicheskoy podgotovlennosti shkolnikov»/Glavnoe upravlenie obrazovaniya administratsii goroda Krasnoyarska. URL: http://krasobr.admkrsk.ru/doc.asp?id = 3598 (data obrascheniya: 11.03 .2014 ).

Рецензенты:

Хазова С.А., д.п.н., профессор кафедры теоретических основ физического воспитания Адыгейского государственного университета, г. Майкоп;

Доронин А.М., д.п.н., профессор кафедры спортивных дисциплин Адыгейского государственного университета, г. Майкоп.

Работа поступила в редакцию 11.04.2014. 